\title{
Chemiluminescence Determination of Mezlocillin by the Luminol-Potassium Periodate System
}

\author{
Wen Bing Shi* and Ji Dong Yang
}

Department of Chemisty and Enviroment Science, Fuling Normal University, Yangtze, Chongqing, 408003, P. R. China

\begin{abstract}
Um método novo, simples e sensível foi proposto para a determinação de mezlocilina. Baseia-se na amplificação da emissão de quimiluminescência (CL) gerada a partir da oxidação do luminol em meio alcalino pelo periodato de potássio. A otimização das variáveis experimentais e instrumentais que afetam o efeito da amplificação de CL foi realizada usando-se sistema de injeção em fluxo. Em condições ótimas, o método é eficiente para determinar mezlocilina no intervalo linear de 0,01 a $30 \times 10^{-6} \mathrm{~g} \mathrm{~mL}^{-1}$ com limite de detecção $(3 \sigma)$ de $3,0 \times 10^{-9} \mathrm{~g} \mathrm{~mL}^{-1}$ e desvio padrão relativo (RSD) de $1,0 \%$ para $1,0 \times 10^{-6} \mathrm{~g} \mathrm{~mL}^{-1}$ de mezlocilina $(n=11)$. O método tem sido aplicado com sucesso, para determinação de mezlocilina em preparações comerciais, amostras sintéticas e formulações biológicas fluidas.
\end{abstract}

A new, simple and sensitive method has been proposed for the determination of mezlocillin. It is based on the enhancement of the chemiluminescence (CL) emission generated from the oxidation of luminol in alkaline medium by postassium periodate. The optimization of the experimental and instrumental variables affecting the CL enhancement effect has been carried out using flow-injection system. In the optimum conditions, the method is efficient to determine mezlocillin in the linear range of $0.01-30 \times 10^{-6} \mathrm{~g} \mathrm{~mL}^{-1}$ with a detection limit $(3 \sigma)$ of $3.0 \times 10^{-9} \mathrm{~g} \mathrm{~mL}^{-1}$ and the relative standard deviation (RSD) is $1.0 \%$ for $1.0 \times 10^{-6} \mathrm{~g} \mathrm{~mL}^{-1}$ mezlocillin $(n=11)$. It has been successfully applied to the mezlocillin determination in commercial preparations, synthetic samples and biological fluids formulations.

Keywords: chemiluminescence, flow injection, mezlocillin

\section{Introduction}

Mezlocillin (Figure 1) is a widely used $\beta$-lactam antibiotic belonging to the penicillin group. It is very effective against some bacteria and is used in treating infections of the skin, blood, central nervous system, respiratory tract, sinuses, and urinary tract. It is also is used to treat some gynecological<smiles>CC(=O)N1CCN(C(=O)N[C@H](C(=O)O)c2ccccc2)C1=O</smiles>

Figure 1. Molecular structure of sodium mezlocillin.

*e-mail: swb02182001@yahoo.com.cn infections of gynecological. ${ }^{1}$ Some other antibiotics given by injection, clavulanic acid, methotrexate and probenecid may interact with mezlocillin. ${ }^{2}$ Therefore, the safety of using mezlocillin is very important, and the biological research of mezlocillin is very significant in clinical medicine. The development of a sensitive and simple method for the determination of mezlocillin is important for quality assurance in preparations and for obtaining optimum therapeutic concentrations. For its measurement, several methods have been reported, such as high-performance liquid chromatography (HPLC), ${ }^{3-9}$ electrochemical ${ }^{10}$ and atomic absorption spectrometry. ${ }^{11}$ The use of chemiluminescence(CL) detection in pharmaceutical analysis involving the assay of active components in dosage forms represents a fairly selective and sensitive technique, which requires relatively simple and inexpensive instrumentation, and a variety of drugs have been determined by this technique. ${ }^{12,13}$ Recently, several CL methods for the determination of penicillin antibiotics have been reported. ${ }^{14-22}$ These were based on enhanced CL methods using luminol-hydrogen peroxide, ${ }^{14}$ enhancing effects on the luminol CL systems, ${ }^{15,20,21}$ quenching CL methods using the 
luminol CL systems, ${ }^{16,17,22}$ and direct CL methods based on potassium superoxide oxidation ${ }^{18}$ or potassium permanganate oxidation. ${ }^{19}$ Moreover, the nature of the reaction mechanism also has been demonstrated in detail. ${ }^{15}$

In this work, a new flow-injection CL method is presented for the determination of mezlocillin which is based on the enhancing effect of mezlocillin on the CL emission generated by the oxidation of luminol with postassium periodate $\left(\mathrm{KIO}_{4}\right)$ in alkaline condition. As far as the authors know, although the CL behaviour of other penicillins has been reported, ${ }^{12-22}$ this is the first use of the luminol- $\mathrm{KIO}_{4}$ reaction for the determination of mezlocillin. Compared with previous CL assays for the determination of penicillin, ${ }^{12-22}$ this method has higher sensitivity (the detection limit is $3.0 \mathrm{ng} \mathrm{mL}^{-1}$ mezlocillin) than previously used oxidants, such as hydrogen peroxide, ${ }^{12}$ potassium ferricyanide, ${ }^{13}$ iodine, ${ }^{14,15}$ superoxide ${ }^{16}$ or potassium permanganate. ${ }^{17}$ The method has been applied to the determination of mezlocillin in pharmaceutical formulations, synthetic samples and biological fluids formulations and the results agreed well with the Pharmacopoeia method. ${ }^{23}$

\section{Experimental}

Reagents

All the reagents used were of analytical reagent grade. Doubly deionized water was used throughout the study. All reagents were obtained from Chongqing Chemical Reagents Company (Chongqing, China) except for luminol, which was purchased from Merck (Darmstadt, Germany) and mezlocillin, which was obtained from Shandong Reyoung Pharmaceutical Co., Ltd., (Shandong, China). A stocked solution of mezlocillin $\left(5 \times 10^{-4} \mathrm{~g} \mathrm{~mL}^{-1}\right)$ was stored in a refrigerator. Working standard solutions of mezlocillin were prepared daily from the stocked solution by appropriate dilution with doubly deionized water. A $0.01 \mathrm{~mol} \mathrm{~L}^{-1}$ luminol solution was prepared by dissolving $0.1777 \mathrm{~g}$ luminol in $100 \mathrm{~mL}$ of $0.01 \mathrm{~mol} \mathrm{~L}^{-1} \mathrm{NaOH}$ solutions. More diluted solutions were prepared in $0.005 \mathrm{~mol} \mathrm{~L}^{-1}$ $\mathrm{NaOH}$ and used immediately. Potassium periodate stock solution $\left(0.01 \mathrm{~mol} \mathrm{~L}^{-1}\right)$ was prepared by dissolving $0.5750 \mathrm{~g}$ potassium periodate in water and diluting to $250 \mathrm{~mL}$ with water. Potassium periodate working solution $\left(5 \times 10^{-5} \mathrm{~mol} \mathrm{~L}^{-1}\right)$ was prepared by diluting above stock solution with water.

\section{Apparatus of flow injection system}

The FIA system (shown in Figure 2) used in this work includes two peristaltic pumps P1 and P2 (Longfang

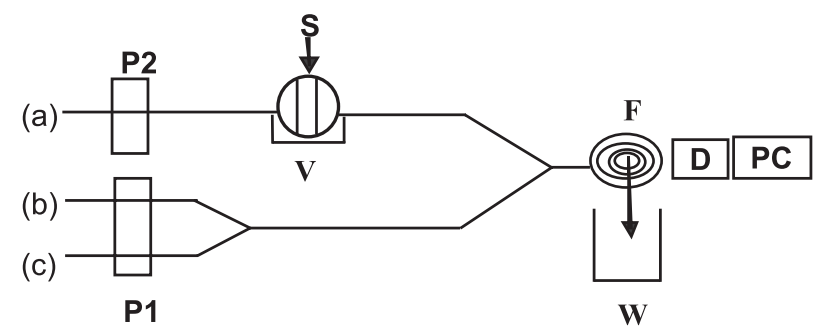

Figure 2. Schematic diagram of the flow system for the determination of mezlocillin. (a) $\mathrm{H}_{2} \mathrm{O}$; (b) $5.0 \times 10^{-5} \mathrm{~mol} \mathrm{~L}^{-1} \mathrm{KIO}_{4}$; (c) $4.0 \times 10^{-5} \mathrm{~mol} \mathrm{~L}^{-1}$ luminol in $5.0 \times 10^{-3} \mathrm{~mol} \mathrm{~L}^{-1} \mathrm{NaOH} ; \mathrm{S}$, sample; $\mathrm{P} 1, \mathrm{P} 2$, peristaltic pump; V, injection valve; F, flow cell; W, waste liquid; D, PMT; PC, personal computer.

Instrument Factory, Wenzhou, China). P1 delivered all reagent streams at a flow rate of $2.5 \mathrm{~mL} \mathrm{~min}^{-1}$ (per tube) and $\mathrm{P} 2$ delivered water carrier stream at a flow rate of $3.6 \mathrm{~mL} \mathrm{~min}^{-1}$, and PTFE tubing $(0.8 \mathrm{~mm}$ i.d.) was used to connect all components in the flow system. A rotary eight-way manual injection valve (Longfang Instrument Factory, Wenzhou, China) was used to inject working and sample solutions into the carrier stream. A volume of $160 \mu \mathrm{L}$ mezlocillin was injected into the water carrier stream and then mixed with a mixture of luminescent reagents (luminol- $\mathrm{KIO}_{4}$ solution). The emitted $\mathrm{CL}$ was collected with a photomultiplier tube (operated at $-600 \mathrm{~V}$ ) of the Type IFFL-DD flow-injection chemiluminescence analyzer (Reike, Xi' an,China). The signal was recorded by using an IBM-compatible computer, equipped with a data acquisition interface. Data acquisition and treatment were performed with REMAX software running under Windows 2000. UV-4100 spectrophotometer (Hitachi, Japan) was used to investigate the UV spectra.

\section{Procedure for calibration}

Some accurately measured aliquots of mezlocillin working standard solutions $\left(5.0 \times 10^{-4} \mathrm{~g} \mathrm{~mL}^{-1}\right)$ in the range of $0.01-30 \times 10^{-6} \mathrm{~g} \mathrm{~mL}^{-1}$ were transferred into a series of $25 \mathrm{~mL}$ volumetric flasks and were diluted with water freshly. The CL signal was measured by injecting $160 \mu \mathrm{L}$ of working standard solution into the water carrier stream, which then joined the reagent streams (a mixture of $5.0 \times 10^{-5} \mathrm{~mol} \mathrm{~L}^{-1}$ $\mathrm{KIO}_{4}$ and $4.0 \times 10^{-5} \mathrm{~mol} \mathrm{~L}^{-1}$ luminol in $5.0 \times 10^{-3} \mathrm{~mol} \mathrm{~L}^{-1}$ $\mathrm{NaOH}$ solution). Calibration graph was constructed by CL emission intensities versus concentration of mezlocillin and the regression equation was calculated.

\section{Procedure for the pharmaceutical preparations}

Injection samples, each with a nominal content of $1.0 \mathrm{~g}$ of mezlocillin in 1 vial were diluted to $1000 \mathrm{~mL}$ with doubly 
deionized water and further diluted to the working range of the determination of mezlocillin. Proceed as described above.

\section{Procedure for synthetical sample}

A certain amount of mezlocillin was put into a $100 \mathrm{~mL}$ flask, and then different foreign substances were added and diluted with doubly deionized water for a quantitative analysis.

\section{Procedure for spiked urine}

Add an aliquot of standard aqueous solution of mezlocillin $\left(5.0 \times 10^{-4} \mathrm{~g} \mathrm{~mL}^{-1}\right)$ to the urine. Transfer 1 $\mathrm{mL}$ of this solution into a $100 \mathrm{~mL}$ volumetric flask and dilute to volume with doubly deionized water. Proceed as described above. A blank value was determined by treating mezlocillin-free urine in the same way.

\section{Procedure for real urine samples}

Take $10 \mathrm{~mL}$ of urine sample from the psychiatric patients suffering from infection of the skin in the local hospital into a clean tube, and then the mixture was diluted ten-fold with doubly deionized water and filtered with $0.45 \mu \mathrm{m}$ filter (Millex-HA, Millipore). The filtrate was treated and analysed according to the the same procedures as those for pharmaceutical samples. A blank value was determined by treating the deionized water in the same way.

\section{Results and Discussion}

\section{Optimization of apparatus parameters}

The flow cell reactor (reaction coil) was made by curling a vitreous tube $(1.5 \mathrm{~mm}$ i.d., $8 \mathrm{~cm})$ and located in front of the photomultiplier; The other apparatus parameters were as follows: flow rates (P1 delivered all reagent streams at a flow rate of $2.5 \mathrm{~mL} \mathrm{~min}^{-1}$ and $\mathrm{P} 2$ delivered water carrier stream at a flow rate of $3.6 \mathrm{~mL} \mathrm{~min}^{-1}$ ); The injected volume is $160 \mu \mathrm{L}$; The distance of valve to flow cell was $8.0 \mathrm{~cm}$; Sampling time was $30 \mathrm{~s}$; The photomultiplier tube was operated at $-600 \mathrm{~V}$.

\section{Optimization of reaction conditions}

It is well known that the luminol CL reaction requires alkaline conditions. Our preliminary experiment showed that among several alkaline buffer solutions tested, including carbonate, phosphate, borate and sodium hydroxide, sodium hydroxide was the most suitable medium for present CL reaction. It was also observed that the $\mathrm{CL}$ reaction has higher CL signal when an appropriate amount of sodium hydroxide was added into the luminol solution than added into the $\mathrm{KIO}_{4}$ solution. Based on these observations, a series of experiments were conducted to select the optimum reaction conditions for the CL determination of mezlocillin using a $1.0 \times 10^{-6} \mathrm{~g} \mathrm{~mL}^{-1}$ mezlocillin standard solution. The parameters included the concentration of sodium hydroxide in the luminol solution, the concentration of $\mathrm{KIO}_{4}$ and the concentration of luminol.

\section{Effect of sodium hydroxide concentration}

The effect of sodium hydroxide (as showed in Figure 3) concentration on the CL reaction was studied at different concentrations from $1.0 \times 10^{-3}$ to $8.0 \times 10^{-2} \mathrm{~mol} \mathrm{~L}^{-1}$ when the concentrations of $\mathrm{KIO}_{4}$ and luminol were fixed at $5.0 \times 10^{-5} \mathrm{~mol} \mathrm{~L}^{-1}$ and $4.0 \times 10^{-5} \mathrm{~mol} \mathrm{~L}^{-1}$, respectively. The $\mathrm{CL}$ intensity continued to increase with the increase in the concentration of sodium hydroxide concentration from $1.0 \times 10^{-3}$ to $5.0 \times 10^{-3} \mathrm{~mol} \mathrm{~L}^{-1}$. When the concentration of sodium hydroxide was higher than $5.0 \times 10^{-3} \mathrm{~mol} \mathrm{~L}^{-1}$, CL intensity decreased. A concentration of $5.0 \times 10^{-3} \mathrm{~mol} \mathrm{~L}^{-1}$ sodium hydroxide was therefore selected for use in the following experiments.

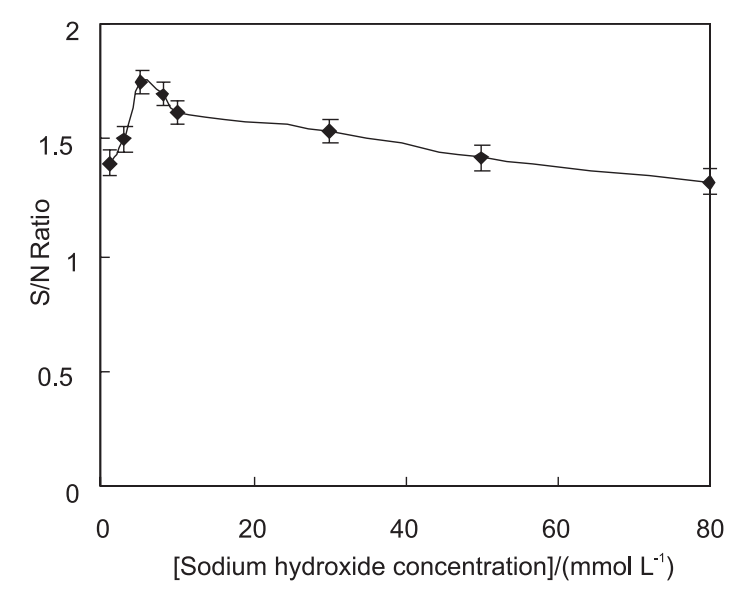

Figure 3. Effect of sodium hydroxide concentration. Error bars represent one standard deviation for five measurements.

\section{Effect of luminol concentration}

As the luminescence reagent, luminol concentration affected the CL intensity (as showed in Figure 4). The effect of $1.0-120 \times 10^{-6} \mathrm{~mol} \mathrm{~L}^{-1}$ luminol on the CL reaction was examined when the concentration of $\mathrm{KIO}_{4}$ was fixed at $5.0 \times 10^{-5} \mathrm{~mol} \mathrm{~L}^{-1}$ and the concentration of sodium hydroxide was fixed at $5.0 \times 10^{-3} \mathrm{~mol} \mathrm{~L}^{-1}$. As the concentration was 
increased, both the CL intensity and the background increased. The maximum signal-to-noise $(\mathrm{S} / \mathrm{N})$ was obtained at $4.0 \times 10^{-5} \mathrm{~mol} \mathrm{~L}^{-1}$ luminol. Therefore, $4.0 \times 10^{-5}$ $\mathrm{mol} \mathrm{L}^{-1}$ luminol was employed in the coming works.

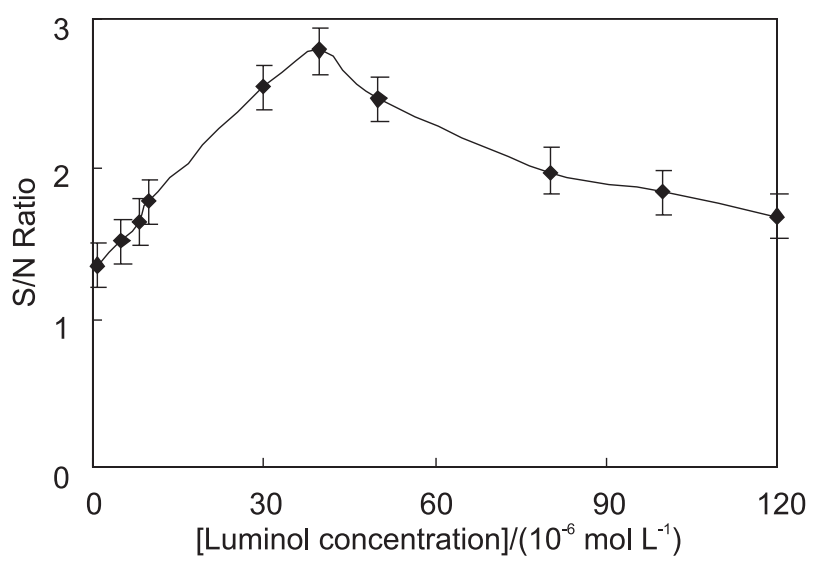

Figure 4. Effect of luminol concentration. Error bars represent one standard deviation for five measurements.

\section{Effect of $\mathrm{KIO}_{4}$}

$\mathrm{KIO}_{4}$ was used as the oxidant in the reaction. The effect of $\mathrm{KIO}_{4}$ concentration (as showed in Figure 5) on the CL reaction was investigated in the range of 0.01 to $1.0 \times 10^{-3}$ mol L-1 when the concentrations of sodium hydroxide and luminol were fixed at $5.0 \times 10^{-3} \mathrm{~mol} \mathrm{~L}^{-1}$ and $4.0 \times 10^{-5}$ mol L $\mathrm{L}^{-1}$ respectively. As the concentration was increased, both the CL intensity and the background increased. The maximum signal-to-noise $(\mathrm{S} / \mathrm{N})$ was obtained at $5.0 \times 10^{-5}$ mol L ${ }^{-1} \mathrm{KIO}_{4}$. So, $5.0 \times 10^{-5} \mathrm{~mol} \mathrm{~L}^{-1} \mathrm{KIO}_{4}$ was selected in the subsequent work.

\section{Performance of the proposed method for mezlocillin measurements}

Under the selected conditions given above, the calibration graph of emission intensity versus mezlocillin concentration was linear in the $0.01-30 \times 10^{-6} \mathrm{~g} \mathrm{~mL}^{-1}$

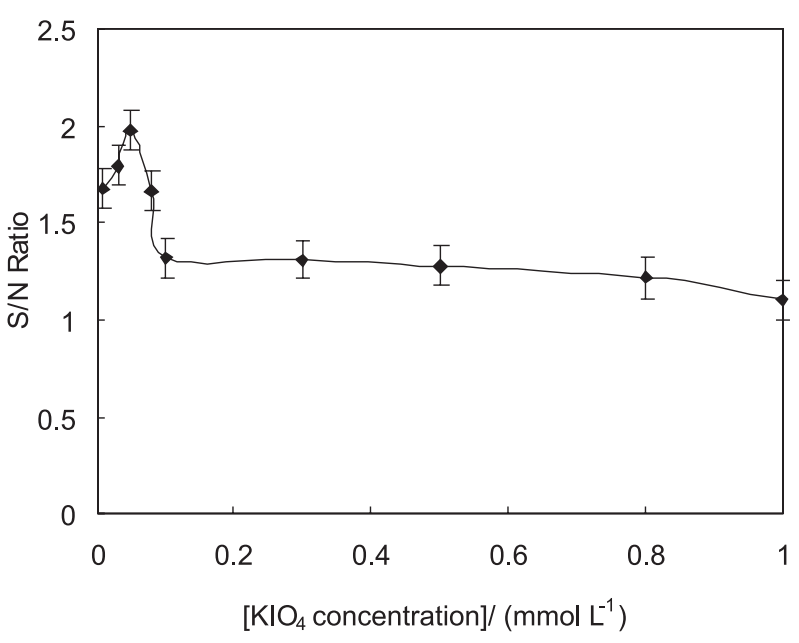

Figure 5. Effect of $\mathrm{KIO}_{4}$ concentration. Error bars represent one standard deviation for five measurements.

range $\left(\Delta \mathrm{I}=54.576\right.$ (mezlocillin) $\left(\times 10^{-6} \mathrm{~g} \mathrm{~mL}^{-1}\right)+580.94$; $r=0.9994, n=11)$ with a detection limit $(3 \sigma)$ of $3.0 \times$ $10^{-9} \mathrm{~g} \mathrm{~mL}^{-1}$. Relative standard deviation (RSD) $(n=11)$ was $1.0 \%$ for $1.0 \times 10^{-6} \mathrm{~g} \mathrm{~mL}^{-1}$ mezlocillin. Seven replicate determinations (determinations of precision and accuracy were performed between 7 days and 7 times in 1 day for intra-day and inter-day, respectively) at four concentration levels were carried out to test the accuracy and precision of the proposed method for urine samples and the results listed in Table 1. As can be seen, RSD (precision) of interday and intra-day is less than 5\%, and accuracy of inter-day and intra-day is satisfactory.

\section{Interference study}

The effect of foreign substances was tested by analyzing a standard solution of mezlocillin $\left(1.0 \times 10^{-6} \mathrm{~g} \mathrm{~mL}^{-1}\right)$ to which increasing amounts of interfering substances was added. The tolerable concentration ratios with respect to $1.0 \times 10^{-6} \mathrm{~g} \mathrm{~mL}^{-1}$ mezlocillin for interference at $\pm 5 \%$ level were over 1000 for starch, glucose, sucrose, $\mathrm{Ca}^{2+} ; 800$ for $\mathrm{Cl}^{-}$, urea, $\mathrm{K}^{+}, \mathrm{Br}^{-}, \mathrm{Na}^{+}, \mathrm{NO}_{3}^{-}$, uric acid, maltose and urea; 600 for $\mathrm{SO}_{4}^{2-}, \mathrm{CO}_{3}^{2-} ; 400$ for paracetamol, respectively.

Table 1. Accuracy and precision data at four concentrations

\begin{tabular}{|c|c|c|c|c|c|c|}
\hline \multirow{2}{*}{$\begin{array}{l}\text { Concentration Added / } \\
\left(\mu \mathrm{g} \mathrm{mL}^{-1}\right)\end{array}$} & \multicolumn{3}{|c|}{ Inter-day ${ }^{\mathrm{a}}$} & \multicolumn{3}{|c|}{ Intra-day $^{\mathrm{a}}$} \\
\hline & Found / $\left(\mu \mathrm{g} \mathrm{mL}^{-1}\right)$ & Error $(\%)$ & $\operatorname{RSD}(\%)$ & Found $/\left(\mu \mathrm{g} \mathrm{mL}^{-1}\right)$ & Error $(\%)$ & $\operatorname{RSD}(\%)$ \\
\hline 0.05 & 0.047 & -6.0 & 4.2 & 0.046 & -0.80 & 2.5 \\
\hline 0.1 & 0.098 & -2.0 & 3.8 & 0.097 & -3.0 & 3.2 \\
\hline 1 & 0.96 & -4.0 & 2.6 & 0.95 & -5.0 & 1.8 \\
\hline 5 & 4.97 & -0.6 & 1.4 & 4.95 & -1.0 & 3.4 \\
\hline
\end{tabular}

${ }^{\mathrm{a}}$ Averages of seven determinations. 
Table 2. Results of the determination of mezlocillin in injections

\begin{tabular}{lccc}
\hline \multirow{2}{*}{ Sample } & Label / $(\mathrm{g})$ & \multicolumn{2}{c}{ Found $/(\mathrm{g}) \pm \mathrm{RSD}(\%)^{\mathrm{a}}$} \\
\cline { 3 - 4 } Injection 1 & 1.00 & Proposed method & UV spectrophotometry \\
Injection 2 & 1.00 & $1.02 \pm 0.28$ & $0.965 \pm 0.36$ \\
Injection 3 & 1.00 & $1.01 \pm 0.46$ & $0.983 \pm 0.52$ \\
\hline
\end{tabular}

${ }^{\mathrm{a}}$ Average of five measurements.

Table 3. Results of the determination of mezlocillin in synthetic samples

\begin{tabular}{clccc}
\hline $\begin{array}{c}\text { Sample } \\
(\text { No. })\end{array}$ & Co-existing substances / $\left(\mu \mathrm{g} \mathrm{mL}^{-1}\right)$ & $\begin{array}{c}\text { Added / } \\
\left(\mu \mathrm{g} \mathrm{mL}^{-1}\right)\end{array}$ & $\begin{array}{c}\text { Found / } \\
\left(\mu \mathrm{g} \mathrm{mL}^{-1}\right)\end{array}$ & $\begin{array}{c}\text { Recovery / } \\
(\% \pm \mathrm{RSD} \%, n=3)\end{array}$ \\
\hline 1 & Glucose (10), starch (10) & 0.5 & 0.49 & $98.0 \pm 3.2$ \\
2 & Glucose (30), starch (30) & 1.0 & 1.02 & $102 \pm 2.4$ \\
3 & Glucose (100), starch (100) & 0.5 & 0.48 & $96.0 \pm 3.6$ \\
4 & Glucose (50), starch (50), urea (50), starch (25) & 1.0 & 0.98 & $98.0 \pm 1.8$ \\
5 & Starch (100), EDTA (5), CaCl $(100)$ & 1.0 & 1.01 & $101 \pm 3.4$ \\
6 & Glucose (100), starch (100), $\mathrm{KCl}(50), \mathrm{MgSO}_{4}(10)$ & 1.0 & 0.99 & $99.0 \pm 2.8$ \\
\hline
\end{tabular}

The results show that the proposed method has good selectivity for mezlocillin determination and it can be used in monitoring the mezlocillin in real samples.

\section{Sample analysis}

Analysis of mezlocillin in injection samples and synthetic samples

Following the procedure described under experimental section, the proposed method was applied to the determination of mezlocillin in injection samples. Also, a series of synthetic samples were prepared to check the validation of the proposed method. The results are listed in Tables 2 and 3. The recovery tests were carried out on the samples and the obtained recoveries were satisfactory. As illustrated in Tables 2 and 3 , the proposed method can be satisfactorily applied to the determination of mezlocillin in injection samples and synthetic samples. The mezlocillin concentrations agree well with those obtained by UV spectrophotometry. The UV spectrophotometric determination of mezlocillin was performed according to the literature.

\section{Analysis of mezlocillin in real urine samples}

As stated above, the proposed method gave a detection limit of $3.0 \times 10^{-9} \mathrm{~g} \mathrm{~mL}^{-1}$ for mezlocillin, which is lower than those given by other methods. For example, Wang et al. ${ }^{11}$ reported a DL of $7.93 \times 10^{-6} \mathrm{~g} \mathrm{~mL}^{-1}$ by atomic absorbption spectrometry. When using high-performance liquid chromatography, ${ }^{8} 1.0 \times 10^{-7} \mathrm{~g} \mathrm{~mL}^{-1}$ in serum and $1.0 \times 10^{-6} \mathrm{~g} \mathrm{~mL}^{-1}$ in urine of DL were reported, respectively. So, the high sensitivity of the proposed method allows the determination of mezlocillin in biological fluids. Table 4 shows the results of mezlocillin determination in urine samples from the patients suffering from infection of the skin.

Table 4. Results of the determination of mezlocillin in urine samples

\begin{tabular}{cc}
\hline Urine sample number & Proposed method / $\left.(\mu \mathrm{g} \mathrm{mL})^{-1}\right)(\mathrm{RSD} \%)^{\mathrm{a}}$ \\
\hline 1 & $1.952(3.82)$ \\
2 & $1.868(2.54)$ \\
3 & $1.924(2.62)$ \\
\hline
\end{tabular}

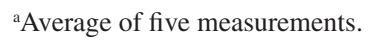

The major urinary metabolite of mezlocillin is penicilloic acid. ${ }^{24}$ Formation of penicilloic acid decreases the potential of protonation as compared with the parent compound. The recovery test on the spiked urine samples at different concentration levels demonstrates good results (shown in Table 5). So, the effect of the urinary metabolites of mezlocillin on the chemiluminescence signal is minor. Results obtained by this proposed method demonstrate that the metabolite of mezlocillin did not affect its determination. 
Table 5. Results of the determination of mezlocillin in spiked urine

\begin{tabular}{cc}
\hline Concentration added $/\left(\mu \mathrm{g} \mathrm{mL}^{-1}\right)$ & Found / $(\%)(\operatorname{RSD} \%, n=3)$ \\
\hline 0.05 & $93.8(2.32)$ \\
0.1 & $93.2(3.26)$ \\
0.2 & $94.4(1.86)$ \\
0.5 & $92.6(1.36)$ \\
0.8 & $95.6(1.80)$ \\
1 & $96.2(2.36)$ \\
10 & $102(2.92)$ \\
\hline
\end{tabular}

\section{Conclusions}

It was found that the reaction medium of the luminol solution, $\mathrm{KIO}_{4}$ and the concentration of mezlocillin affected the $\mathrm{CL}$ intensitivity. In alkaline medium, mezlocillin showed strong CL enhancement at $5.0 \times 10^{-3} \mathrm{~mol} \mathrm{~L}^{-1}$ sodium hydroxide. On this basis, a flow injection method was established for the determination of mezlocillin. This method has the merits of higher sensitivity and wider linear range, being superior to the literature methods. It is applicable to detect mezlocillin in pharmaceutical formulations, synthetic samples and biological fluids formulations.

\section{Acknowledgments}

This work is supported by the Chongqing Committee of Education (No. KJ061306).

\section{References}

1. Betriu, C.; Sánchez, A.; Gómez, M.; Palau, M. L.; Picazo, J. J.; J. Antimicrob. Chemother. 1999, 43,133.

2. Trissel, L. A.; Martinez, J. F.; Gilbert, D. L.; J. Am. Pharm. Assoc. (Wash) 1999, 39, 514.

3. Haginaka, J. J.; Wakai, H.; Yasuda, U. T.; Anal. Sci. 1985, 1, 73.

4. Fiore, D.; Auger, F. G.; Drusano, G. L.; Dandu, V. R.; Lesko, L. J.; Antimicrob. Agents Chemother. 1984, 26, 775.
5. Haen, E.; Remien, J.; Richter, E.; Frank, U.; Adam, D.; Biopharm. Pharmacokinet, Eur. Congr. 1984, 2, 318.

6. Knoller, J.; Bremm, K. D.; Schoenfeld, W.; Koenig, W.; Antimicrob. Agents Chemother. 1986, $29,527$.

7. Kames, H. T.; Beightol, L. A.; Farthing, D.; Ther. Drug Monit. 1987, 9, 456.

8. Garca-Glez, J. C.; Mendez, R.; Martn-Villacorta, J.; J. Chromatogr. A 1998, 812, 213.

9. Zhao, Y. C.; Liao, Z. X.; Chin. J. Pharm. 2002, 33,139.

10. Ning, M. X.; Cheng, F. L.;Wu, J.; J. Instrum. Anal. 2003, 22,12 .

11. Wang, S. Z.; Meng, S. M.; Guo, Z. Y.; J. Yanb. Norm. U. 2003, $19,46$.

12. Calokerinos, A. C.; Deftereos, N. T.; Baeyens, W. R. G.; J. Pharm. Biomed. Anal. 1995, 13,1063.

13. Fuster Mestre, Y.; Lahuerata Zamora, L.; Martinez Calatayud, J.; Luminescence 2001, 16, 213.

14. Ros, M.; Karge, E.; Klinger, W.; J. Biolumin. Chemilumi. 1998, 13, 355.

15. Kubo, H.; Saitoh, M.; Murase, S.; Inomata, T.; Yoshimura, Y.; Nakazawa, H.; Anal. Chim. Acta 1999, 389, 89.

16. Ventura, S.; Silva, M.; Perez-Bendito, D.; Anal. Chim. Acta 1992, 266, 301

17. Min, R.W.; Nielsen, J.; Villadsen, I.; Anal. Chim. Acta 1995, 312,149 .

18. Sun, J.; Schulman, S. G.; Perrin, J. H.; Anal. Chim. Acta 1997, $338,1$.

19. Du, J.; Li, Y.; Lu, J.; Anal. Lett. 2002, 35, 2295.

20. Yinhuan, L.; Yuhai, T.; Hong, Y.; Junmei, F.; Luminescence 2003, 18, 313 .

21. Hiroaki, K.; Masatoshi, S.; Anal. Sci. 1999, 15, 919.

22. Gregorio Alaponta, A.; Lahuerta Zamoraa, L.; Martínez Calatayud, J.; J. Pharm. Biomed. Anal. 1999, 21, 311.

23. Pharmacopoeia of People's Republic of China, part II, Chemical Industry Press: Beijing, 2000.

24. Kees, F.; Naber, K. G.; Bartoschik-Wich, B.; Stockmann, P.; Arzneimittel forschung 1985, 35, 1097.

Received: August 11, 2007

Web Release Date: July 25, 2008 